\title{
O PAPEL DA GESTÃO ESCOLAR E DO PROJETO POLÍTICO PEDAGÓGICO NA INCLUSÃO EDUCACIONAL ${ }^{1}$
}

\author{
Amós Santos Silva ${ }^{2}$ \\ Carla Mylena Florêncio da Silva ${ }^{3}$ \\ Orquídea Maria de Souza Guimarães ${ }^{4}$
}

\begin{abstract}
Resumo: O artigo discute o papel da gestão escolar e do projeto político pedagógico no processo de inclusão educacional, visando analisar a atuação destes na implantação de uma cultura escolar inclusiva, considerando práticas pedagógicas como o espaço para Atendimento Educacional Especializado (AEE). A abordagem qualitativa orientou a observação participante registrada em diário de campo, tendo como participantes a gestão escolar de uma escola pública em Caruaru-PE. Percebemos que a gestão escolar nas ações conjuntas voltadas ao processo inclusivo dos alunos atendidos pelo AEE, provê recursos humanos, materiais e financeiros que são fundamentais ao processo de aprendizagem dos alunos.
\end{abstract}

Palavras-chave: Gestão Escolar. Educação Inclusiva. Projeto Político Pedagógico.

\section{THE ROLE OF SCHOOL MANAGEMENT AND THE PEDAGOGICAL POLITICAL PROJECT IN EDUCATIONAL INCLUSION}

\begin{abstract}
:
This paper discusses the role of school management and the pedagogical political project in the process of educational inclusion, aiming to analyze their role in the implementation of an inclusive school culture, considering pedagogical practices such as the Specialized Educational Service (ESA). The qualitative approach guided the participant observation recorded in field diary, taking as participants the school management of a public school in Caruaru-PE. We realize that school management in the joint actions geared to the inclusive process of the students attended by the ESA, provides human, material and financial resources that are fundamental to the learning process of the students.
\end{abstract}

Keywords: School Management. Inclusive education. Political Pedagogical Project.

\footnotetext{
${ }^{1}$ Uma versão preliminar e parcial do trabalho foi apresentada no II Congresso Internacional de Educação Inclusiva e II Jornada Chilena Brasileira de Educação Inclusiva, Campina Grande-PB, 2016.

${ }^{2}$ Graduando em Pedagogia na Universidade Federal de Pernambuco (UFPE/CAA), bolsista do Programa Institucional de Bolsa de Iniciação à Docência (PIBID) e membro do GEECAMPO (Grupo de Estudo e Pesquisa da Educação do Campo), e do Grupo de pesquisa Formação de Professor e Profissionalização Docente (UFPE/CAA). E-mail: amosantoss10@gmail.com

${ }^{3}$ Graduanda em Pedagogia na Universidade Federal de Pernambuco (UFPE/CAA) e professora da educação infantil na rede municipal de ensino de Caruaru-PE. E-mail: carlamylena33@gmail.com

${ }^{4}$ Doutora em Educação pela Universidade Federal de Pernambuco, professora Adjunta do Centro Acadêmico do Agreste - UFPE, no Núcleo de Formação Docente, atuando no Curso de Graduação em Pedagogia. Participa dos grupos de pesquisa: Discursos e Práticas Educacionais; e Formação de Professor e Profissionalização Docente, ambos da UFPE e registrados no Diretório de Pesquisa do CNPq. E-mail: orquídea.sguimaraes@ufpe.br
} 


\section{INTRODUÇÃO}

A Inclusão educacional obteve inúmeros avanços e transformações no que diz respeito à legislação, bem como na sua efetivação para a convergência da melhoria no atendimento de crianças e adolescentes nas escolas regulares. Com a formulação de leis e elaboração de declarações e programas em prol da defesa do deficiente, a educação inclusiva tornou-se uma das temáticas mais debatidas pelos órgãos educacionais com relação ao acesso, permanência e melhoria da educação brasileira. A inclusão dos alunos passou a ser pensada com o intuito de promover o desenvolvimento dos educandos deficientes, possibilitando oportunidades igualitárias e levando-os a alcançar o sucesso escolar.

A compreensão da educação inclusiva nesta perspectiva está relacionada a uma nova concepção de educação e de prática educacional propostas pelas diversas políticas educacionais para essa área. Nestas políticas educacionais fica também explicito que o desafio de subverter a hegemonia de uma "cultura escolar segregadora" e de possibilitar a reinvenção dos princípios e práticas escolares que garantam o direito à educação de todos indistintamente, está posto sobre todos os profissionais que compõe a rede educacional (gestores, professores, especialistas, pais, etc..), visto que Ferreira (2013) sublinha a necessidade da participação para a reestruturação das culturas, políticas e práticas das escolas que, como sistemas abertos, precisam rever suas ações, até então, predominantemente elitistas e excludentes.

Nesse contexto de mudanças sobre os conceitos, a legislação, as práticas educacionais e de gestão em que a escola vem passando ao longo dos anos, pensá-la tornou-se tarefa desafiante e complexa. Tendo em vista a complexidade da construção dos métodos de planejamento e suas contribuições para a instituição escolar inclusiva, o trabalho da gestão escolar desenvolve-se na organização das condições de acesso aos espaços, aos recursos pedagógicos, e à comunicação interacional entre todos que compõem a gestão, para que favoreçam a promoção da aprendizagem e a valorização das diferenças.

Em virtude disto, neste presente trabalho estudamos acerca do papel da gestão escolar na organização do trabalho pedagógico da escola, trabalho este que aborde o desenvolvimento de 


\section{REVISTA DE ADMINISTRAÇÃO EDUCACIONAL}

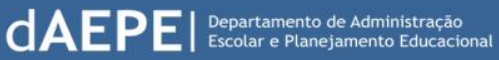

ações voltadas para o processo inclusivo de alunos com necessidades especiais, e que propiciem condições para a aprendizagem desses sujeitos. Buscamos assim, investigar as ações de organização do trabalho pedagógico da escola e o papel da gestão no desenvolvimento de tais ações que incluam esses alunos no âmbito escolar, inclusão esta que esta salvaguardada pela Constituição Federal e Lei de Diretrizes e Bases da Educação Nacional (Lei nº 9394/96) afirmando que a educação é um direito de todos.

Neste trabalho propomos a seguinte problematização: Como se dá a atuação da gestão escolar na inclusão dos alunos com necessidades especiais no ensino regular?. Elencando como objetivo geral da atividade compreender a atuação da gestão escolar na inclusão dos alunos com necessidades especiais no ensino regular, e após, desmembramos como objetivos específicos primeiramente analisar como o Projeto Político Pedagógico (PPP) contempla a inclusão de alunos com necessidades especiais, e por fim, visamos caracterizar as ações da gestão escolar no desenvolvimento da organização do trabalho pedagógico voltadas para o processo inclusivo destes alunos.

\section{Educação Inclusiva e o Papel do Projeto Político-Pedagógico na Organização do Trabalho Pedagógico Inclusivo}

De um modo mais amplo compreendemos ancorados nas contribuições teóricas acerca da inclusão educacional que esta, e consequente o conceito de não-inclusão, exprime-se por três dimensões que interagem e ao mesmo tempo se complementam. Nesta direção entendemos que existem interligadas as dimensões das políticas inclusivas, a da cultura inclusiva e a das práticas inclusivas.

Ao abordar sobre tais dimensões em suas teorizações no texto "Inclusão: Desenvolver a aprendizagem e a participação nas escolas”, Booth e Ainscow (2000) apontam que a primeira refere-se à inclusão como o centro do desenvolvimento e de transformação da escola, esta permeando todas as ações que visem à melhoria da aprendizagem e a participação de todos os alunos. São estas consideradas como apoio as atividades que ampliem e fortaleçam a capacidade da escola de responder e corresponder à diversidade de seus alunos.

No que tange a dimensão da cultura inclusiva estes autores afirmam que a mesma traz a possibilidade de se criar na escola uma comunidade acolhedora e colaboradora, de modo que 


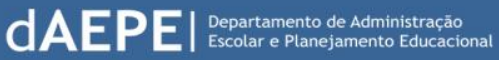

todos sejam respeitados e valorizados. Por fim, porém não menos importante, evidenciamos a dimensão das práticas educativas, esta que por sua vez reflete as duas já citadas anteriormente, na qual assegura que todas as atividades - sejam as de sala de aula e/ou as extraescolares promovam a participação e o engajamento de todos os alunos, considerando seus conhecimentos e suas vivências dentro ou fora do âmbito escolar (BOOTH \& AINSCOW, 2000).

Concomitantemente, a integração escolar é o processo de ensinar crianças consideradas "normais $5 \%$ juntos com crianças com alguma deficiência, em que na maioria das vezes, não existe preocupação de perceber se as crianças deficientes estão verdadeiramente inclusas naquele ambiente, e se está sendo respeitada a diversidade existente nas mesmas.

Para Carvalho (1937, p. 36):

A integração escolar tem sido conceitualizada como um processo de ensinar/educar crianças ditas normais junto com crianças portadoras de deficiências, durante sua permanência na escola. Trata-se de um processo gradual e dinâmico, que assume várias formas segundo as necessidades e características de cada aluno, sempre levando-se em consideração o seu contexto socioeconômico.

Neste sentido, o processo de integração é aquele que em geral ocorre nas escolas, pois, colocam-se crianças consideradas "normais" no mesmo espaço das crianças com deficiência, não importando assim se as crianças deficientes estão se sentindo incluídas naquele espaço.

Por outro lado, à inclusão ocorre quando se considera a escola como um espaço para todos no sentido literal da palavra, ou seja, quando se inclui estes sujeitos com necessidades especiais de forma que se reconhece e se respeita à diversidade existente, e assim dirigir-se a cada um de acordo com suas necessidades, pois, como declara Carvalho (1937, p. 38) “A educação inclusiva tem sido conceituada como um processo de educar conjuntamente e de maneira incondicional, nas classes do ensino comum, alunos ditos normais, com alunos que apresentem necessidades educacionais especiais". Nisto fica perceptível que a inclusão aponta

\footnotetext{
${ }^{5}$ Segundo a Organização Mundial de Saúde (OMS), deficiência é o substantivo atribuído a toda perda ou anormalidade de uma estrutura ou função psicológica, fisiológica ou anatômica, Referindo-se, portanto, à biologia do ser humano. Assim, os indivíduos que apresentam comprometimento da capacidade motora, visual, mental ou auditiva, fogem dos padrões considerados "normais" para a maioria da sociedade, visto que comumente é chamada "criança normal" as que não possuem tais deficiências.
} 


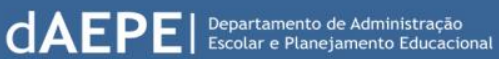

para um novo percurso no que diz respeito as minorias educacionais, pois, "A inclusão vem quebrar barreiras cristalizadas em torno de grupos estigmatizados” (WERNECK, 1997, p. 42).

No Brasil na década de 1960 à educação especial - denominada de "Educação de Excepcionais" - era considerada uma modalidade transversal em relação às demais, sendo assim constitucionalizada como tal através da Lei de Diretrizes e Bases da Educação Nacional LDBEN (Lei $n^{\circ} 4.024 / 61$ ). Não havendo desta forma melhoria na educação inclusiva, esforços foram empreendidos como uma tentativa de "destransversalização" dessa modalidade de ensino tomamos como exemplo à promulgação da Lei 5.692/71 (LDBEN). No entanto, tal lei não obteve muita efetivação, até que ocorrera a elaboração das leis na Constituição Federal de 1988 quando o princípio da educação inclusiva (Educação e igualdade de direitos para todos) fortaleceu-se incentivado pela criação de leis, declarações e programas.

Quando fora oficializada na LDB - Lei de Diretrizes e Bases n ${ }^{\circ} 9.394$ promulgada em 20 de dezembro de 1996 - este sistema modular do "ensino especial", apresenta-se como algo à preencher as lacunas nas legislações anteriores, pois, a partir da lei nº 9.394, na seção V:

Art. $58^{\circ}$ : Entende-se por educação especial, para os efeitos desta Lei, a modalidade de educação escolar oferecida preferencialmente na rede regular de ensino, para educandos com deficiência, transtornos globais do desenvolvimento e altas habilidades ou superdotação (BRASIL, 1996, p. 35).

Bem como expressam no art. $59^{\circ}$ da referida lei e seção, as obrigatoriedades dos sistemas de ensino no que tange à seguridade para com os alunos:

Art. $59^{\circ}$. Os sistemas de ensino assegurarão aos educandos com deficiência, transtornos globais do desenvolvimento e altas habilidades ou superdotação: $\S 1^{\circ}$. Currículos, métodos, técnicas, recursos educativos e organização específica, para atender às suas necessidades; $\S 2^{\circ}$.Terminalidade específica para aqueles que não puderem atingir o nível exigido para a conclusão do ensino fundamental, em virtude de suas deficiências, e aceleração para concluir em menor tempo o programa escolar para os superdotados;§ $4^{\circ}$. Educação especial para o trabalho, visando a sua efetiva integração na vida em sociedade, inclusive condições adequadas para os que não revelarem capacidade de inserção no trabalho competitivo, mediante articulação com os órgãos oficiais afins, bem como para aqueles que apresentam uma habilidade superior nas áreas artística, intelectual ou psicomotora; $\S 5^{\circ}$. Acesso igualitário aos benefícios dos programas sociais suplementares disponíveis para o respectivo nível do ensino regular (BRASIL, 1996, p. $38)$.

Observamos que a escola, como espaço inclusivo, objetiva considerar o sucesso de todos seus alunos sem exceção, elaborando um projeto educativo que considere as diferenças. Esse projeto educativo impele uma busca pela participação de todos na construção de novas práticas 


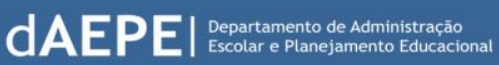

pedagógicas para esses sujeitos, portanto, este trabalho pedagógico provém de iniciativas que envolvem professores, gestores, pais e alunos, e que juntos constroem uma proposta que abarque as peculiaridades de cada escola.

Deste modo Projeto Político Pedagógico ${ }^{6}$ (PPP) apresenta-se como o instrumento legal para desenvolver o plano de trabalho que fora eleito e definido por um coletivo escolar, pois, ele reflete as especificidades da escola que o produziu, bem como suas escolhas e peculiaridades. $\mathrm{O}$ PPP deve ser compreendido como norteador de todo trabalho pedagógico desenvolvido na escola, pois, o mesmo dever ser entendido “[...] como a própria organização do trabalho pedagógico de toda escola" (VEIGA, 2004, p. 13).

O PPP da escola pública de ensino regular deve contemplar o Atendimento Educacional especializado (AEE), isto feito na compreensão do mesmo como uma das dimensões da própria escola. Tal obrigatoriedade legal encontra-se descrita no Decreto $n^{\circ} 6.571$, de 18 de setembro de 2008 que instituiu as Diretrizes Operacionais da Educação Especial para o Atendimento Educacional Especializado - AEE na educação básica. Encontramos descrito na referida lei que $\operatorname{diz}$ :

A oferta do atendimento educacional especializado - AEE deve constar no Projeto Pedagógico da escola de ensino regular, prevendo na sua organização: a. Sala de recursos multifuncional: espaço físico, mobiliários, materiais didáticos, recursos pedagógicos e de acessibilidade e equipamentos específicos; b. Matrícula do aluno no AEE: condicionada à matrícula no ensino regular da própria escola ou de outra escola; c. Plano do AEE: identificação das necessidades educacionais específicas dos alunos, definição dos recursos necessários e das atividades a serem desenvolvidas; cronograma de atendimento dos alunos; d. Professor para o exercício da docência do AEE; e. Profissionais da educação: tradutor e intérprete de Língua Brasileira de Sinais, guiaintérprete e outros que atuam no apoio às atividades de alimentação, higiene e locomoção. f. Articulação entre professores do AEE e os do ensino comum. g. Redes de apoio: no âmbito da atuação intersetorial da formação docente, do acesso a recursos, serviços e equipamentos, entre outros que contribuam para a realização do AEE (BRASIL, 2008, p. 03).

Observamos em todas estas diretrizes, que o PPP ao abordar e institucionalizar o AEE na escola proporcionará meios para o atendimento dessa demanda, isto feito a partir dos objetivos e metas propostas no projeto educativo. Bem como o PPP estabelecerá formas de

\footnotetext{
${ }^{6}$ Veiga (2004) define o Projeto Político Pedagógico como algo além de um simples agrupamento de planos de ensino e de atividades diversas. O mesmo é projeto porque é construído coletivamente por meio de planejamento, é político porque articula-se os interesses reais e coletivos da população majoritária ao compromisso sociopolítico, e por fim é pedagógico, pois, possui o sentido de definir as ações educativas para cumprir seus propósitos e intencionalidades.
} 


\section{REVISTA DE ADMINISTRAÇÃO EDUCACIONAL}

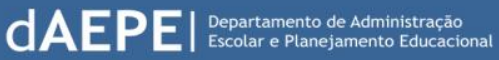

avaliação do AEE, seja para alteração de práticas, ou para inserção de novos objetivos e metas, visando a sua melhoria. E no que concerne o processo de avaliação do serviço ofertado, cabe à gestão o acompanhamento e o controle para o melhor desenvolvimento do atendimento, pois, conforme afirma Libâneo, Oliveira, Toschi (2003, p. 350) “A avaliação é função primordial do sistema de organização e de gestão, [...] a avaliação permite pôr em evidência as dificuldades surgidas na prática diária, e [...] visa ao melhoramento do trabalho escolar, pois, se pode assim analisar suas causas e encontrar meios de sua superação”.

Nesta compreensão do PPP como agente definidor dos fundamentos da estrutura escolar, observamos que o mesmo deve ser coerente com as proposições de uma educação que engloba as diferenças, e que de fato oferta à igualdade de condições para acesso e permanência de todos na escola.

\section{Gestão Democrática Participativa e a Organização do Trabalho Pedagógico para a Inclusão}

\section{Educativa}

Segundo Libâneo, Oliveira, Toschi (2003, p. 315) "O sistema de organização e de gestão da escola é o conjunto de ações, recursos, meios e procedimentos que propiciam as condições para alcançar os objetivos da instituição escolar”. Portanto, à gestão escolar desenvolve o gerenciamento das instituições de ensino, mobilizando os processos e recursos de forma intencional e sistemática, tendo como objetivo prioritário o desenvolvimento da aprendizagem dos alunos.

Nessa premissa de sistema de organização e de planejamento das ações, compreendemos também a gestão escolar a partir de Paro (2008) como sendo uma atividade que não se preocupa com o esforço despendido por pessoas separadamente, porém feita com o esforço humano coletivo, surgindo o que o autor chama de "coordenação" que trata-se da organização humana da atividade. E assim Libâneo, Oliveira, Toschi (2003) reitera que o processo de trabalho da gestão escolar tem natureza interativa, bem como seus objetivos são voltados para a educação e a formação de pessoas.

$\mathrm{Na}$ Constituição Federal de 1988, a gestão democrática participativa foi institucionalizada no artigo 206, que se explicitou como um dos princípios basilares para a 


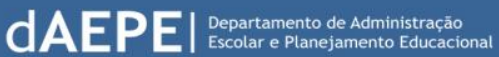

educação no Brasil "[...] à gestão democrática do ensino público". Dentre os principais artigos da referida lei, destacamos os que afirmam os seguintes princípios dessa gestão:

Art. 14. Os sistemas de ensino definirão as normas da gestão democrática do ensino público na educação básica, de acordo com as suas peculiaridades e conforme os seguintes princípios: I. Participação dos profissionais da educação na elaboração do projeto pedagógico da escola; II - Participação das comunidades escolar e local em conselhos escolares ou equivalentes (BRASIL, 1998, p. 25).

Nessa ênfase dada ao projeto pedagógico da escola e na sua proposta de construção e administração ancorada na gestão democrática, Botler (2007, p. 38) afirma que a gestão democrática está “[...] associada ao fortalecimento da ideia de democratização do trabalho pedagógico, entendida como participação de todos nas decisões e na sua efetivação". Esta seria base da verdadeira escola democrática inclusiva, voltada para uma ação coletiva e coordenada, aonde todos os envolvidos seriam sujeitos ativos nesse processo.

A gestão escolar, que se diz democrática participativa, se distingue em várias características das outras concepções de gestão escolar. Esta se encontra articulada as atividades da direção com os demais segmentos da escola, onde todos participam das tomadas de decisão, dando ênfase de maneira igualitária às tarefas e às relações, valorizando os elementos internos do processo organizacional (LIBÂNEO, OLIVEIRA, TOSCHI, 2003).

A gestão escolar é fundamental para o desenvolvimento pedagógico da escola, por ser capaz de proporcionar abertura de novos espaços para transformação do cotidiano escolar. Para que suas ações no processo de inclusão se efetivem é necessário à flexibilidade do seu trabalho, considerando importante pensar à diversidade de opiniões.

Como reitera Sage (1999):

O diretor deve ser o principal revigorador do comportamento do professor que demonstra pensamentos e ações cooperativas a serviço da inclusão. É comum que os professores temam inovação e assumam riscos que sejam encarados de forma negativa e com desconfiança pelos pares que estão aferrados aos modelos tradicionais. O diretor é de fundamental importância na superação dessas barreiras previsíveis e pode fazê-lo através de palavras e ações adequadas que reforçam o apoio aos professores (SAGE, 1999, p. 138).

Observamos que Sage (1999) analisa a importância do diretor para as ações que podem ser desenvolvidas no âmbito escolar, mostrando que este deve encorajar os professores para que os objetivos propostos para a inclusão dos alunos especiais possam ser alcançados. A gestão 


\section{REVISTA DE ADMINISTRAÇÃO EDUCACIONAL}

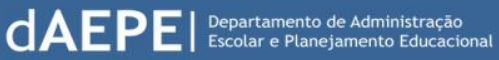

escolar tem o dever de tomar iniciativas, inclusive de cunho administrativo, para a implantação de projetos de educação inclusiva.

Ressaltamos também a importância do Decreto $\mathrm{n}^{\mathrm{o}}$ 7.611, de 17 de novembro de 2011, que instituiu o Atendimento Educacional Especializado (AEE), na qual denota mais uma vez como a pauta da educação especial vem sendo cada vez mais discutida, bem como à compreensão do espaço escolar como célula mater na promulgação da democracia, visto que possibilitar o acesso/permanência de todos à educação - independentemente das condições primárias - se configura conforme Veiga (2004, p. 17) uma demonstração de que a organização do trabalho em uma escola democrática, pública e gratuita norteia-se, entre outros princípios, pela: igualdade de condições para acesso e permanência na escola.

O AEE é um serviço gratuito aos estudantes com deficiência, transtornos globais do desenvolvimento e altas habilidades e/ou superdotação, devendo ser oferecido de forma transversal a todos os níveis, etapas e modalidades. De acordo com o decreto, o Atendimento Educacional Especializado compreende um conjunto de atividades, recursos de acessibilidade e pedagógicos, organizados institucional e continuamente, e prestados de forma complementar na formação dos estudantes com necessidades especiais.

Desta forma para uma melhoria na inclusão e na qualidade de ensino dos alunos atendidos pelo AEE, é necessária uma articulação conjunta entre os professores, coordenadores, gestores etc., sobre a elaboração de planos de trabalho para o atendimento educacional especializado, visto que conforme explicita Lück (2013, p.22) “O alcance dos objetivos educacionais depende do emprego adequado da energia dinâmica das relações dos diversos atores da comunidade escolar nos processos decisórios da escola de modo a constituir um empenho coletivo em torno de sua realização".

\section{PERCURSO METODOLÓGICO}

A pesquisa realizada foi fundamentada em uma abordagem de pesquisa qualitativa e exploratória, através do estudo de campo. Conforme André (1995, p. 17) a pesquisa qualitativa se caracteriza por ser um "[...] estudo do fenômeno em seu acontecer natural" se opondo ao 


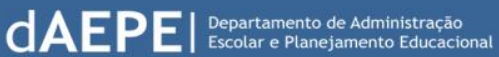

método quantitativo de pesquisa, levando em conta todos os componentes de uma situação. Já a pesquisa exploratória conforme Gil (2002) tem o objetivo de:

[...] proporcionar maior familiaridade com o problema, com vistas a torná-los mais explícito ou a constituir hipóteses. Pode-se dizer que estas pesquisas têm como objetivo principal o aprimoramento de ideias ou a descoberta de intuições. Seu planejamento é, portanto, bastante flexível, de modo que possibilite a consideração dos mais variados aspectos relativos ao fato estudado (GIL, 2002, p. 41).

Desta forma no estudo de campo, o pesquisador realiza a maior parte do trabalho pessoalmente, pois é enfatizada a importância de o pesquisador ter tido ele mesmo uma experiência direta com a situação de estudo. A pesquisa teve como campo de análise uma escola municipal de Caruaru, que atende alunos do ensino infantil e fundamental I em sua unidade e em seu anexo escolar.

Tomamos como sujeitos para nossa pesquisa à gestão escolar, que é composta pela gestora, formada em Pedagogia e com dois anos e meio na gestão da escola; uma gestora adjunta, formada em Pedagogia e também com dois anos e meio na gestão; um auxiliar administrativo, sem nenhuma formação superior e com dois anos no cargo; uma secretária, formada em Pedagogia e com três anos na função; dois coordenadores pedagógicos, formados em Pedagogia, com três e dois anos e meio nas suas funções. Também tomaremos como sujeito a psicopedagoga que trabalha com o AEE na escola.

A pesquisa contou como instrumentos para colher os dados e para alcançar seus objetivos, à observação direta utilizada para obter informações e para analisar os sentidos de determinados aspectos da realidade. Também tivemos a anotação em diário de campo dos fatos observados e das conversas informais tidas com os sujeitos.

Analisou-se também o PPP da referida escola, a fim de perceber se ocorre a materialização do mesmo no trato para com as questões de inclusão de alunos especiais, pois, “A escola é o lugar de concepção, realização e avaliação de seu projeto educativo, uma vez que necessita organizar seu trabalho pedagógico com base em seus alunos” (VEIGA, 2004, p. 13).

Os dados foram analisados por meio dos objetivos, divididos em dois tópicos. Primeiro através do exame do PPP foi possível tratar do primeiro objetivo, e no segundo analisamos por meio da observação e das anotações nos diários de campo, onde construímos uma grelha de 


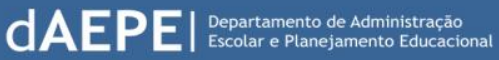

dados para organizar as informações. Chegando assim aos resultados, que foram expostos também agrupados em dois tópicos de acordo com cada objetivo.

\section{RESULTADOS E DISCUSSÃO DOS DADOS}

\section{A Inclusão Escolar no Projeto Político e Pedagógico (PPP)}

Ao analisarmos o Projeto Político e Pedagógico (PPP) da escola em questão percebemos que este não trata sobre a inclusão dos alunos com necessidades especiais na escola. Entendemos que isto pode ser considerado como um ponto negativo para a escola, já que compreendemos o Projeto Político e Pedagógico da escola como o norteador de tudo o que se realizará nela, como explicita Veiga (2004, p. 13) ele é “entendido como a própria organização do trabalho pedagógico de toda a escola". Diante disso, vemos a necessidade de se ter tratado neste documento da escola uma questão que é presente e de muita importância, como todas as outras que estão presentes nele, que é a inclusão dos alunos portadores de necessidades especiais.

A escola possui um Regimento Escolar, que é considerado, segundo a gestora como "as leis e os artigos de acordo com a constituição e a Lei de Diretrizes e Bases" (fragmento de diário de campo 01). Neste Regimento foi observado que trata sobre o atendimento aos alunos portadores de necessidades especiais, porém se resumindo a tratar apenas sobre a Sala de Recursos. Nele analisamos que aborda a finalidade desta sala, que é "oferecer Atendimento Educacional Especializado aos alunos com necessidades especificas/especiais" (SEÇÃO III, Art. 62. Anexo). Como é realizado este atendimento, que se dá "por um professor especializado, portador de graduação superior, além de participar de formações continuadas especificas para esse exercício" (SEÇÃO III, Art. 63. Anexo) e se direciona "alunos e as famílias, com o objetivo de discutir e somar as responsabilidades sobre as ações pedagógicas a serem desenvolvidas" (SEÇÃO III, Art. 64. Anexo). Por fim, aponta quais as atribuições deste professor que trabalhará com o AEE. Uma destas atribuições é “identificar, elaborar, produzir e organizar serviços, recursos pedagógicos, de acessibilidade e estratégias considerando as necessidades especificas dos alunos público-alvo da Educação Especial” (SEÇÃO III, Art. 65. I, Anexo). 


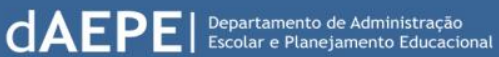

Mesmo compreendendo que o Regimento Escolar se diferencia do Projeto Político e Pedagógico, constatamos que o que está presente no Regimento se materializa nas ações desenvolvidas pela escola. A sala de recursos existe e é de fato direcionada para o AEE. A professora que faz este atendimento é graduada em pedagogia e pós-graduada em psicopedagogia, ela atende aos alunos com necessidades especiais, com exceção dos alunos com deficiência motora. Seu trabalho é organizado, elaborado e acompanhado em conjunto com a gestão da escola e também por órgãos superiores.

Apesar disto, não deixamos de conceber a importância que existe de ser abordada no Projeto Político e Pedagógico, de maneira mais ampla e diversificada a inclusão de alunos portadores de necessidades especiais.

\section{A Participação da Gestão Escolar no Processo de Inclusão Escolar}

Através da observação, podemos perceber que a gestão dentro de sua limitação atua de maneira participativa no processo inclusivo dos alunos com necessidades especiais. Durante nossas observações notamos que na estrutura física do colégio tem uma escada que dificultava o acesso de crianças com dificuldades motoras, sendo assim, a gestão inverteu a biblioteca com uma sala de aula, colocando a sala de aula para baixo e a biblioteca para cima, adaptando o ambiente dentro da limitação da escola. Além disso, observamos que a equipe gestora é quem organiza o horário da sala do AEE e faz o acompanhamento junto com a professora responsável pela sala para saber se os alunos estão conseguindo se desenvolver, sempre perguntando se ela está precisando de algum recurso material para auxiliá-la no atendimento.

Convém ressaltar que a gestora faz um encaminhamento, solicitando um cuidador para aqueles alunos que possui alguma necessidade especial mais agravada e que precise de apoios nas questões relacionadas à saúde, higiene, mobilidade e/ou deslocamentos do aluno. Destacamos ainda que a sala do AEE não se restringe apenas a atender a demanda da escola, mas sim a comunidade e alunos de escolas circunvizinhas que não possuem sala de recurso.

Outros aspectos que percebemos, foi a integração que existe entre a família dos alunos com necessidades especiais e a escola, pois sempre que surge alguma dúvida da família ou alguma dificuldade em questão a gestora solicita uma conversa para que os pais tirem as possíveis dúvidas e colaborem com as atividades proposta pela professora do AEE para que os 


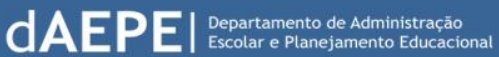

resultados sejam os melhores. Além dessa integração com os pais sempre ocorre momentos de discussão com os professores das salas de aulas para que haja uma colaboração entre os mesmos e a professora do AEE.

Da mesma forma, a supervisora faz o acompanhamento das faltas dos alunos, caso o aluno falte com bastante frequência, é perpassado para a gestora, para que esta ligue para os responsáveis para saber qual o motivo da falta da criança. Segundo a supervisora isso é de fundamental importância "para saber o que a criança tem, pois, às crianças com necessidades especiais, principalmente os autista, quando têm crises passam duas ou três semanas sem frequentar a escola, e muitos pais não ligam em avisar" (fragmento de diário de campo). Ainda assim, segundo a supervisora "as avaliações para alguns dessas crianças com necessidades é diferente das provas dos demais alunos, pois a avaliação se dá a partir da necessidade desse aluno respeitando a sua limitação" (fragmento de diário de campo).

Durante uma conversação que tivemos com a secretária, ela nos disse que "a gestora sempre faz o possível para dar o maior suporte para os professores e para as crianças com necessidades especiais" (Diário de Campo, 2016). Como observamos na fala da secretária “caso surja alguma criança com necessidades especiais e mesmo que não tenha a vaga, a gestora faz sempre o possível para encaixá-la” (Diário de Campo, 2016). Nessa perspectiva, percebemos que as ações que a equipe gestora faz, são de grande importância para a construção de uma escola inclusiva, e apesar das limitações que a escola possui, fazem sempre o que está ao alcance para dar um melhor atendimento a essas crianças que necessitam de cuidados especiais.

\section{CONSIDERAÇÕES FINAIS}

Consideramos que a legislação brasileira vem avançando no sentido de garantir à educação como direito de todos. Dessa forma, percebemos que as pessoas portadoras de deficiência além do total direito de estudar em uma escola de ensino regular, passam a ter também nesse momento, a oportunidade para tal, e assim exercem sua função de cidadão.

Em conseguinte, compreendemos que apesar do PPP da escola pesquisada - algo que nos propomos analisar - não tratar sobre a inclusão dos alunos com necessidades especiais, este tema é contemplado no Regimento Escolar, o qual se restringe apenas à sala do AEE. Desse modo notamos que independente disto, na escola ocorre de fato à inclusão desses alunos, 


\section{REVISTA DE ADMINISTRAÇÃO EDUCACIONAL}

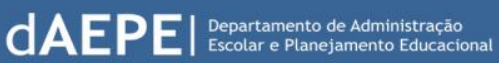

mesmo com toda limitação que ela possui, à gestão escolar esforça-se ao máximo para adaptar o ambiente para o aluno, sempre respeitando sua limitação.

Percebemos que à gestão escolar ao desenvolver ações voltadas para o processo inclusivo de alunos com necessidades especiais, promove o desencadeamento na construção coletiva de uma escola que possibilite uma educação igualitária para todos. Pois cabe ao gestor escolar prover recursos materiais, financeiros e humanos, que são fundamentais para o desenvolvimento do processo de aprendizagem dos alunos com necessidades especiais. Diante disto, consideramos que a gestão da escola atua de modo ativo participativo na inclusão dos alunos com necessidades especiais.

Concluímos então, que a escola não exclui esses alunos e que também não tem suas propostas de inclusão apenas nos papéis e documentos legais da mesma. Ela atua de maneira eficaz, proporcionando a esses alunos com necessidades educacionais especiais uma educação igualitária e de qualidade.

\section{Referências}

ANDRÉ, M. E. D. A. Etnografia da Prática Escolar. Campinas, SP, 1995.

BOOTH, T.; AINSCOW, M. Index for Inclusion: developing learning and participation in schools. Bristol: CSIE, 2000.

BRASIL. Lei de Diretrizes e Bases da Educação: Lei 9.394/96. Brasília, 1996.

Secretaria de Educação à Distância. Educação Especial: tendências atuais, saltos para o futuro. Brasília, 1999.

Ministério da Educação. SECADI. Política Nacional de Educação Especial na

Perspectiva da Educação Inclusiva, 2008. Disponível em: Acesso em: 08 julho de 2016.

CARVAlHO, R. E. Removendo Barreiras para a Aprendizagem. Editora mediação, 1937. 


\section{REVISTA DE ADMINISTRAÇÃO EDUCACIONAL}

Escola Inclusiva: a reorganização do trabalho pedagógico. Editora mediação, 1937.

FIGUEIREDO, R. V. A formação de professores para a inclusão dos alunos no espaço pedagógico da diversidade. In: MANTOAN, Maria Tereza Eglér (Org.). O desafio das diferenças nas escolas. 1 ed. Petrópolis: Vozes, 2008, v. 1, p. 141-145. Disponível em:<http://www.aprendizagemnadiversidade.ufc.br/documentos/inclusao_escolar/a_formacao.pd f>. Acesso em: 23 Jun. 2016.

GIL, A. C. Como Elaborar Projetos de Pesquisar. São Paulo, 2002.

JOVER, A. Preparando a Escola Inclusiva. In: Revista Nova Escola. Editora Abril, nº123, 1999.

LIBÂNEO, J. C.; OLIVEIRA, J. F.; TOSCHI, M. S. Educação escolar: políticas, estrutura e organização. São Paulo: Cortez, 2003. (Coleção Docência em Formação).

MACHADO, R. Educação Especial na Escola Inclusiva: Políticas, Paradigmas e Práticas. Cortez editora, 1967.

MANTOAN, M. T. E. A Integração de Pessoas com Deficiência: contribuições para uma reflexão sobre o tema. São Paulo: Memnon. Editora SENAC, 1997.

PARO, V. H. Administração escolar: introdução crítica. 16. ed. São Paulo: Cortez, 2010.

RODRIGUES, David (Org.). Inclusão e Educação: Doze olhares sobre a educação inclusiva. São Paulo: Summus, 2006. 


\section{REVISTA DE ADMINISTRAÇÃO EDUCACIONAL}

SAGE, D. D. Estratégias administrativas para a realização do ensino inclusivo. In: STAINBACK, Susan; STAINBACK William (Orgs.). Inclusão: um guia para educadores. Porto Alegre: Artes Médicas, 1999.

VEIGA, I. P. A. Educação básica: Projeto politico-pedagógico; Educação Superior; Projeto politico-pedagógico. Campinas, SP: Papirus, 2004.

WERNECK, C. Ninguém Mais Vai Ser Bonzinho na Sociedade Inclusiva. Rio de Janeiro, WVA, 1997. 